\title{
Two decades of pediatric lung transplant in the United States: Have we improved?
}

\author{
Farhan Zafar, MD, Jeffrey S. Heinle, MD, Marc G. Schecter, MD, Joseph W. Rossano, MD, \\ George B. Mallory, Jr, MD, Okan Elidemir, MD, and David L. S. Morales, MD
}

\begin{abstract}
Objective: Since 1988, approximately 1100 pediatric lung transplants have been performed worldwide with consistent improvement in survival. Similarly, survival for pediatric heart transplant has increased over the years; however, in this cohort improvement in survival is exclusively a result of increased early (1-year) survival. To observe if this same phenomenon exists in pediatric lung transplants, the United Network for Organ Sharing database was analyzed to evaluate and characterize how pediatric lung transplant survival has changed in the past 2 decades.
\end{abstract}

Methods: The United Network for Organ Sharing database was queried for patients aged 18 years or less who underwent lung transplantation from May 1988 to May 2008. Analysis included 959 pediatric lung transplants.

Results: Age groups were infants $(\leq 1$ years $)(n=106[11 \%])$, children $(2-12$ years $)(n=299[31 \%])$, and adolescents $(\geq 13$ years) $(\mathrm{n}=554[58 \%])$. A total of $546(57 \%)$ were girls. Kaplan-Meier survival was significantly better in the late era (2002-2008) than in all other eras $(1988-1994$ and 1995-2001) $(P<.05)$. The half-life for graft has increased significantly over the eras (early, 2.2 years; mid, 3.3 years; and late, 3.8 years). Conditional 1-year survival (ie, mid to late survival) was not significantly different $(P=.3)$ among the eras. Gender, age, diagnosis, prolonged ischemic time, and cytomegalovirus mismatch did not significantly affect overall patient or graft survival. Chronic preoperative steroid dependence $(P=.02)$, preoperative ventilatory dependence $(P<.001)$, and retransplantation $(P=.02)$ were associated with decreased survival.

Conclusions: Survival in pediatric lung transplant has increased significantly over the years, but this improvement primarily reflects improvement in early survival. Survival in pediatric lung transplant after the first posttransplant year has not changed in more than 2 decades. (J Thorac Cardiovasc Surg 2011;141:828-32)

B Supplemental material is available online.

The first human lung transplant was performed by Dr James Hardy at the University of Mississippi in 1963 for an isolated cancer of the lung. ${ }^{1}$ Between 1963 and 1980, approximately 44 transplants were performed at medical centers around the world with no real success. Most of these transplants were performed on debilitated patients as "rescue" attempts after they became ventilator-dependent. Only 2 recipients lived more than 1 month. The advent of new techniques and immunosuppressive therapies made possible the first successful single lung transplant, which was performed

From the Michael E. DeBakey Department of Surgery, Division of Congenital Heart Surgery, Baylor College of Medicine, Houston, Tex.

Disclosures: Authors have nothing to disclose with regard to commercial support.

Presented at the 29th Annual Meeting of The International Society for Heart \& Lung Transplantation, April 22-25, 2009, Paris, France.

Received for publication Feb 9, 2010; revisions received April 19, 2010; accepted for publication June 1, 2010; available ahead of print Jan 21, 2011.

Address for reprints: Farhan Zafar, MD, Congenital Heart Surgery, Texas Children's Hospital, 6621 Fannin Street MC-WT 19345H, Houston, TX 77030 (E-mail: fxzafar@texaschildrenshospital.org).

0022-5223/\$36.00

Copyright (C) 2011 by The American Association for Thoracic Surgery doi:10.1016/j.jtcvs.2010.06.067 by Dr Joel D. Cooper in 1983. This achievement was followed by the first successful double lung transplant in $1986 .^{2}$

The first pediatric lung transplant (PLT) was performed at the University of Toronto in 1987 in a 15-year-old boy with familial pulmonary fibrosis. ${ }^{3}$ However, lung transplantation in children has not been as widely embraced as in the adult population. Since 1988, more than 1100 PLTs have been performed worldwide, with consistent improvement in survival. In recent years, approximately 70 to 75 PLTs have been performed yearly in 28 centers across the world, with only 2 centers performing more than 10 transplants each year. ${ }^{4}$

Since the 1980s, survival in pediatric heart transplantation has improved significantly. ${ }^{5}$ However, the present authors previously demonstrated that all improvements in survival were in reality only an increase in early survival. ${ }^{6}$ After the first posttransplant year, survival in pediatric heart transplantation has not changed in more than 2 decades. To observe whether the same phenomenon exists in PLT, an analysis of all the PLTs recorded in the Organ Procurement and Transplantation Network (OPTN) Thoracic Registry was undertaken.

\section{MATERIALS AND METHODS}

A retrospective analysis of OPTN data as of May 2008 was performed. The OPTN is the unified transplant network established by the United 


\section{Abbreviations and Acronyms}

$\mathrm{BO}=$ bronchiolitis obliterans

OPTN $=$ Organ Procurement and Transplantation Network

PLT = pediatric lung transplant
States Congress under the National Organ Transplant Act of 1984. The United Network for Organ Sharing is a private, nonprofit organization that administers the OPTN under federal contract.

Analysis was limited to patients in the United Network for Organ Sharing/OPTN Thoracic database who were aged less than 18 years and who underwent lung transplantation between May of 1988 and May of 2008. Of a total of 17,207 lung transplants, $959(5.5 \%)$ were PLTs. Patients were divided according to the year of transplant into 3 groups: early (1988-1994), mid (1995-2001), and late (2002-2008) eras.

There were 490 possible data points; many of these fields were infrequently populated. Therefore, the analysis was limited only to the variables that were at least $80 \%$ populated, with the exception of cytomegalovirus mismatch for which only $40 \%$ had the information available. Twentyfive variables met this criterion; on the average, these variables were $95 \%$ populated. For baseline characteristics, continuous variables were compared using $t$ test and analysis of variance, with the Tukey method for controlling for multiple comparisons. Categoric variables were compared using the chi-square test. Survival curves were estimated using the Kaplan-Meier method, and equality of survival curves was tested using a log-rank test. Multivariate analyses were performed using Cox proportional hazards regression models.

\section{RESULTS}

\section{Demographics}

The mean age and weight of the recipients were $12 \pm 5.6$ years and $33.6 \pm 16.3 \mathrm{~kg}$, respectively, and the mean age and weight of the donors were $17.6 \pm 15$ years and 41.6 $\pm 24 \mathrm{~kg}$, respectively. A total of $106(11 \%)$ of the total cohort were infants (aged $\leq 1$ year), $299(31 \%)$ were aged 2 to 12 years, and $554(58 \%)$ were adolescents (aged $\geq 13$ years). A total of $546(57 \%)$ were girls. Ethnic composition of the cohort was Caucasian $(83 \%, 795)$, Hispanic $(8 \%$,
80), African American (5\%, 50), and others (4\%, 34). Some $51 \%$ (490) of the cohort had a gender-matching transplant. Gender-mismatch transplants consisted of female recipients who had a male donor $(29 \%, 273)$ and male recipients who had a female donor $(20 \%, 196)$. Some $48 \%$ (264/554) of the adolescents had an adult donor. A median of 51 (1-73) transplants were performed each year over the 20 years, and a median of 60 (57-62) transplants were performed over the last 5 years.

\section{Pretransplant Characteristics}

Pretransplant diagnosis was cystic fibrosis in 505 patients $(53 \%)$, primary pulmonary hypertension in 104 patients $(11 \%)$, transplant-related bronchiolitis obliterans (BO) in 50 patients $(5 \%)$, primary BO in 34 patients $(3.5 \%)$, interstitial lung disease in 32 patients ( $3 \%$ ), and other diseases in 218 patients $(28 \%)$. Incidences of different diagnosis are outlined in Table E1 (available online). Some $31 \%$ of patients (298) were receiving steroids, and $16 \%$ of patients (155) were ventilator dependant at the time of transplant; $7 \%$ of patients (64) had a pan-resistant bacterial infection before transplant, and in the last 2 years this incidence had significantly increased $(P<.001)$ to $22 \%(17 / 76)$; $13 \%$ of patients (125) had a previous thoracic operation that was nontransplant related. Median overall waiting time was 5 (0-96) months. Infants (1 [0-7] months) had a significantly shorter $(P<.001)$ waiting time than those aged 2 to 12 years (4 [0-84] months) and adolescents (8 [0-96] months).

\section{Transplantation and Posttransplant Characteristics}

Bilateral lung transplantation was performed in $94 \%$ (899) of the cohort, and retransplantation was performed in $8 \%(81)$ of the cohort. A living donor transplant was performed in $11 \%$ (106) of PLTs, with only $2(1.5 \%)$ performed in last 3 years. Mean organ ischemic time was $5 \pm 2$ hours.
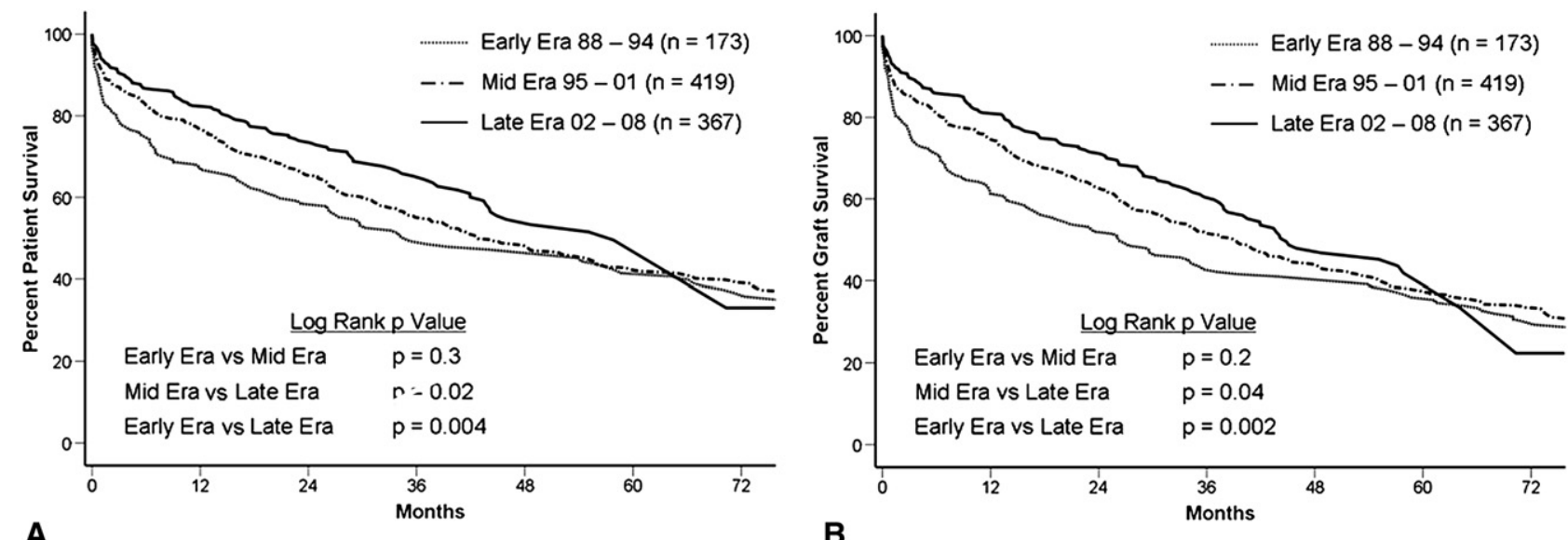

FIGURE 1. Kaplan-Meier curves: patient survival in different eras (A) and graft survival in different eras (B). 


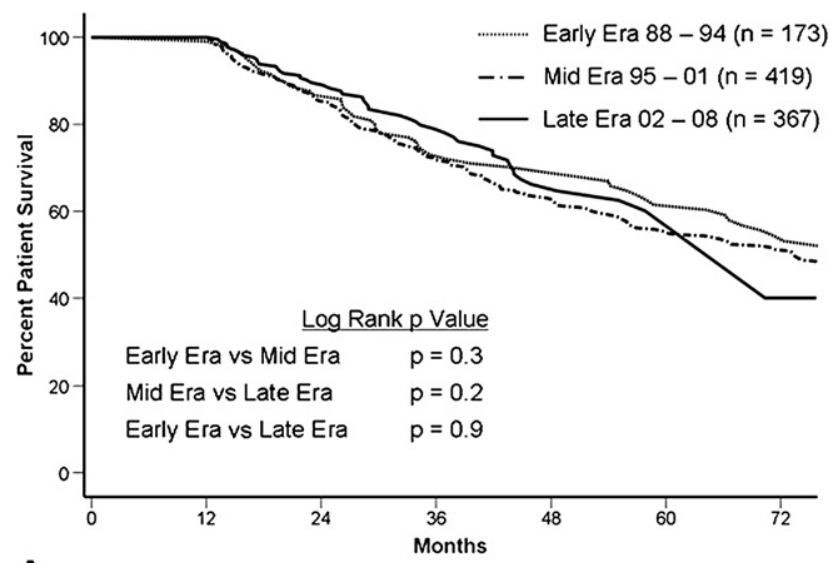

A

Incidences of posttransplant morbidities were as follows: infection requiring treatment $46 \%$ (441), bronchial stricture $3 \%$ (27), and airway dehiscence $0.8 \%$ (8). Median length of hospital stay was 19 days (1-326 days), and this has not changed significantly $(P>.05)$ among the eras.

\section{Patient and Graft Survival}

Kaplan-Meier survivals (both patient and graft) were significantly better in the late era compared with the other 2 eras $(P<.05)$ (Figure 1). Kaplan-Meier survival conditional on 1 year was not significantly different $(P>.2)$ among the eras (Figure 2) for patient or graft. Some 51\% (490) of the cohort were reported as dead. The cause of death was graft failure in 35\% (169) and infection in $23 \%$ (114). Causes of death are outlined in Table E2 (available online). Overall graft survival is shown in Figure 3. Table 1 shows overall graft survival and comparison of survival for different eras at 1,3 , and 5 years. Patient survival for children aged 2 to 12 years was better than for children aged 13 to 18 years; however, graft survival was not significantly different among age groups (Figure 4).

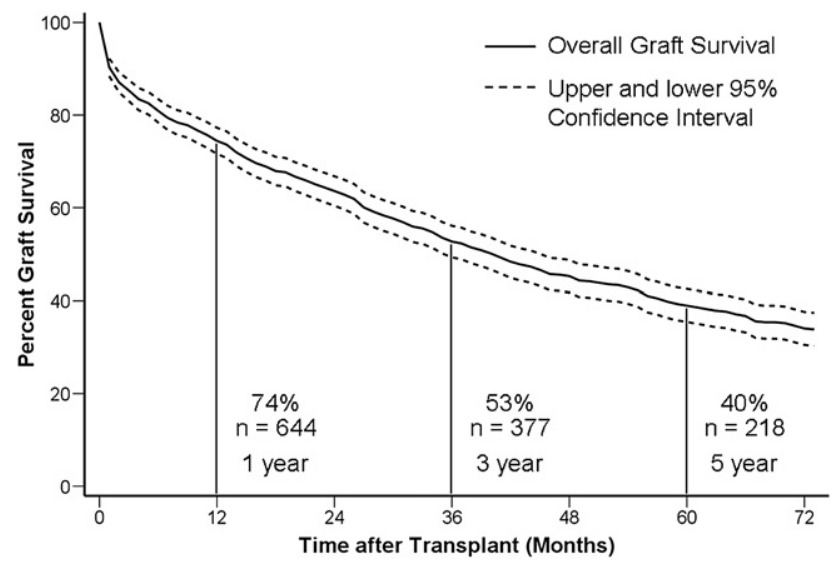

FIGURE 3. Overall graft survival.

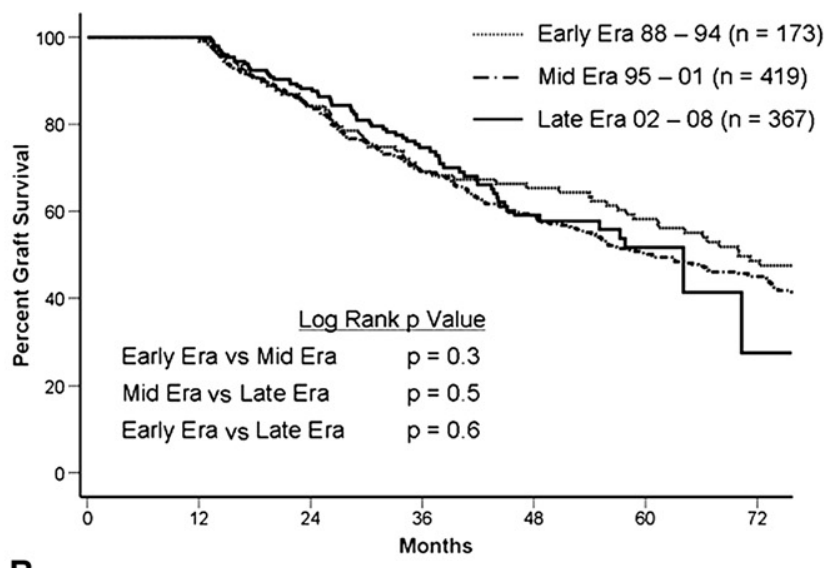

B

\section{Multivariate Analyses of Patient Survival}

Gender, age groups, diagnosis, and cytomegalovirus mismatch did not significantly affect overall patient or graft survival. Chronic steroid dependence $(P=.02)$, pretransplant ventilator dependence $(P<.001)$, and retransplantation $(P=.02)$ were associated with significantly increased overall mortality (Table 2$)$. The risk factors for early mortality $(\leq 1$ year) were the same as for overall mortality. However, there were no risk factors found to be associated with late mortality ( $>1$ year).

\section{DISCUSSION}

Lung transplantation has moved into a new era of success with 3 major changes: (1) the advent of currently used surgical techniques by Patterson and associates, ${ }^{7}$ addressing the issues of airway anastomosis and prolonged ischemia; (2) the introduction of cyclosporine in 1983, which resulted in dramatically improved survival; and (3) the adoption of close collaboration between the medical and surgical teams in the care of these patients that has continued to improve outcomes.

The results of the current analysis substantiate the inference made by the 2008 International Society for Heart \& Lung Transplantation registry that survival in the late era of PLT is significantly greater than in the earlier eras. ${ }^{4}$ This difference is clearly driven by an improvement in 1-year (early) survival as highlighted by the conditional 1-year survival curves that are virtually identical for the different eras (Figure 2). These survival curves censor 1-year mortality so

TABLE 1. Graft survival

\begin{tabular}{lcccc}
\hline \multicolumn{5}{c}{ Graft survival } \\
\hline & Overall & Early era & Mid era & Late era \\
\hline $1 \mathrm{y}$ & $74 \%$ & $62 \%$ & $75 \%$ & $81 \%$ \\
$3 \mathrm{y}$ & $53 \%$ & $43 \%$ & $52 \%$ & $61 \%$ \\
$5 \mathrm{y}$ & $40 \%$ & $36 \%$ & $38 \%$ & $43 \%$ \\
Half life & $3.4 \mathrm{y}$ & $2.2 \mathrm{y}$ & $3.3 \mathrm{y}$ & $3.8 \mathrm{y}$ \\
\hline
\end{tabular}



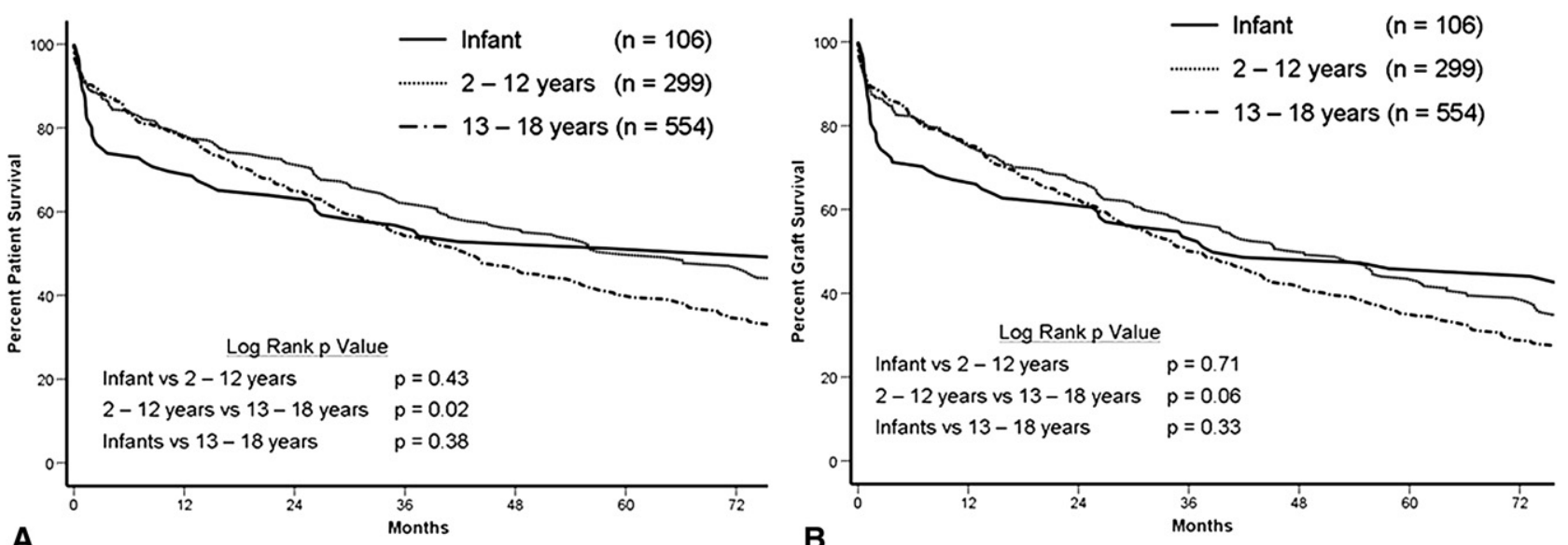

FIGURE 4. Kaplan-Meier curves: patient survival for different age groups (A) and graft survival for different age groups (B).

that a direct comparison of midterm and late survival is possible. We reported the same phenomenon in pediatric heart transplantation. ${ }^{6}$ This improvement in early PLT survival is likely due to advances in surgical, anesthetic, and critical care management, and improvements in lung preservation, infection control, and strategies to combat early rejection. Also, the refinement in candidate selection over the years as the field has matured likely has helped to improve early survival. For example, unlike in the 1990s, few centers would now perform transplantation in patients with cystic fibrosis who are on ventilators. However, no significant advances have been made to treat chronic rejection in pediatric lung or heart transplantation since the introduction of cyclosporine in 1983. BO remains the most common cause of PLT graft failure beyond the first year of transplant. ${ }^{4}$ Enormous amounts of work have been done recently to understand early diagnosis and treatment of BO ${ }^{8-10}$ However, despite shifting trends in immunosuppression (ie, increased use of mycophenolate, sirolimus, and tacrolimus), the mortality rate for PLT after the first posttransplant year has not changed in more than 20 years. ${ }^{4}$

TABLE 2. Risk factors analyzed for graft loss

\begin{tabular}{lccc}
\hline \multicolumn{3}{c}{ Multivariate survival analysis } \\
\hline & & \multicolumn{2}{c}{$\mathbf{9 5 \%}$ CI } \\
\cline { 2 - 4 } & Hazard ratio & Lower & Upper \\
\hline Gender (female) & 1.058 & .831 & 1.346 \\
Gender-mismatch & 1.118 & .853 & 1.465 \\
Age & 1.015 & .996 & 1.034 \\
Diagnosis (cystic fibrosis) & 1.096 & .837 & 1.436 \\
Pretransplant steroid dependence & $\mathbf{1 . 2 7 4}$ & $\mathbf{1 . 5 8 2}$ & $\mathbf{1 . 0 2 7}$ \\
Pretransplant ventilator dependence & $\mathbf{1 . 7 8 9}$ & $\mathbf{2 . 3 0 4}$ & $\mathbf{1 . 3 8 7}$ \\
Retransplantation & $\mathbf{1 . 6 8 1}$ & $\mathbf{2 . 6 6 0}$ & $\mathbf{1 . 0 6 3}$ \\
Ischemic time $>$ 6 h & 1.122 & 1.385 & 0.908 \\
Pretransplant pan-resistant bacterial & 1.222 & 1.821 & 0.821 \\
$\quad$ infection & & & \\
CMV mismatch & 1.222 & 1.821 & 0.821 \\
\hline
\end{tabular}

$C I$, Confidence interval; $C M V$, cytomegalovirus.
Pretransplant chronic steroid use, ventilator dependence, and retransplantation were found to be independent risk factors for poor graft survival, as has been reported by other groups. ${ }^{11,12}$ Although mechanical ventilation is a significant risk factor for morbidity and mortality in adults and older children, the impact on infants is less clear. ${ }^{13,14}$ Nonetheless, in this analysis pretransplant mechanical ventilatory support is an independent risk factor for graft failure at all ages. In this cohort, mid to late survival ( $>1$ year) seemed to be unaffected by any of the variables analyzed.

Although there is conflicting evidence regarding the impact of pretransplant pan-resistant bacterial infection on the outcome of lung transplant recipients, ${ }^{15-18}$ the present study did not show it to be a risk factor for mortality. However, a significant increase over the past few years in the incidence of pan-resistant bacterial infection is noted at the time of registration, which is concerning because it is common to isolate identical bacteria from the lungs of patients after lung transplantation compared with those infecting the patients preoperatively. ${ }^{19}$ Gram-negative infection in patients with cystic fibrosis, particularly certain Burkholderia cepacia complex infections, has been associated with poor outcomes and early mortality posttransplant. ${ }^{19,20}$ Burkholderia cenocepacia (previously known as Genomovar 3), a virulent species of Burkholderia, is considered an absolute contraindication to lung transplantation in most centers. Although the use of multiple combinations of bactericidal antibiotics for eradication of Burkholderia species has been proposed, empiric evidence of successful outcome after lung transplantation, especially in regard to B. cenocepacia, is still lacking.

\section{CONCLUSIONS}

Early posttransplant survival has significantly improved to such an extent that it has prolonged the overall survival after PLT dramatically. Unfortunately, chronic rejection continues to dominate late graft survival with little 
improvement in affective therapies. Therefore, in patients surviving the first posttransplant year, the subsequent mortality rate has not changed in more than 2 decades. There is an increasing need for novel therapies focused on improving the long-term survival in these patients.

\section{References}

1. Reitz BA, Wallwork JL, Hunt SA, et al. Heart-lung transplantation: successful therapy for patients with pulmonary vascular disease. N Engl J Med. 1982;306:557-64

2. Toronto Lung Transplant Group. Unilateral lung transplantation for pulmonary fibrosis. N Engl J Med. 1986;314:1140-5.

3. Grossman RF, Frost A, Zamel N, et al. Results of single-lung transplantation for bilateral pulmonary fibrosis. N Engl J Med. 1990;322:727-33.

4. Aurora P, Edwards BL, Christie J, et al. Registry of the International Society for Heart and Lung Transplantation: Eleventh Official Pediatric Lung and Heart/ Lung Transplantation Report-2008. J Heart Lung Transplant. 2008;27:978-83.

5. Kirk R, Edwards LB, Aurora P, et al. Registry of the International Society for Heart and Lung Transplantation: Eleventh Official Pediatric Heart Transplantation Report-2008. J Heart Lung Transplant. 2008;27:970-7.

6. Morales DL, Dreyer WJ, Denfield SW, et al. Over two decades of pediatric heart transplantation: how has survival changed? J Thorac Cardiovasc Surg. 2007;133: 632-9.

7. Patterson GA, Cooper JD, Dark JH, et al. Experimental and clinical double lung transplantation. J Thorac Cardiovasc Surg. 1988;95:70-4.

8. Sharples LD, McNeil K, Stewart S, et al. Risk factors for bronchiolitis obliterans: a systematic review of recent publications. J Heart Lung Transplant. 2002;21: 271-81.

9. Khalifah AP, Hachem RR, Chakinala MM, et al. Minimal acute rejection after lung transplantation: a risk for bronchiolitis obliterans syndrome. Am J Transplant. 2005;5:2022-30.
10. Tamm M, Sharples LD, Higenbottam TW, et al. Bronchiolitis obliterans syndrome in heart-lung transplantation: surveillance biopsies. Am J Respir Crit Care Med. 1997;155:1705-10.

11. Starnes VA, Bowdish ME, Woo MS, et al. A decade of living lobar lung transplantation: recipients outcomes. J Thorac Cardiovasc Surg. 2004;127: 114-22.

12. Sweet SC. Pediatric lung transplantation. Proc Am Thorac Soc. 2009;6:122-7.

13. Trulock EP, Christie JD, Edwards LB, et al. Registry of the International Society for Heart and Lung Transplantation: Twenty-Fourth Official Adult Lung and Heart-Lung Transplantation Report-2007. J Heart Lung Transplant. 2007;26: 782-95.

14. Elizur A, Sweet SC, Huddleston CB, et al. Pre-transplant mechanical ventilation increases short-term morbidity and mortality in pediatric patients with cystic fibrosis. J Heart Lung Transplant. 2007;26:127-31.

15. Griffith B, Hardesty R, Armitage J, et al. A decade of lung transplantation. Ann Surg. 1993;218:310-20.

16. Aris RM, Gilligan PH, Neuringer IP, et al. The effect of panresistant bacteria in cystic fibrosis patients on lung transplantation outcome. Am J Respir Crit Care Med. 1997;155:699-704.

17. Dobbin C, Maley M, Harkness J, et al. The impact of pan-resistant bacterial pathogens on survival after lung transplantation in cystic fibrosis: results from a single large referral centre. J Hosp Infect. 2004;56:277-82.

18. Hadjiliadis D, Steele MP, Chaparro C, et al. Survival of lung transplant recipients with cystic fibrosis harboring panresistant bacteria other than B cepacia, compared to patients harboring sensitive bacteria. J Heart Lung Transplant. 2003; 22(Suppl):190S-1.

19. Chaparro C, Maurer J, Gutierrez C, et al. Infections with Burkholderia cepacia in cystic fibrosis: outcomes following lung transplantation. Am J Respir Crit Care Med. 2001;163:43-8.

20. Aris RM, Routh JC, LiPuma J, et al. Lung transplantation for cystic fibrosis patients with Burkholderia cepacia complex: survival linked to genomovar type. Am J Respir Crit Care Med. 2001;164:2102-6. 
TABLE E1. Pretransplant diagnosis

\begin{tabular}{lcr}
\hline \multicolumn{1}{c}{ Diagnosis } & Frequency & Percent \\
\hline Cystic fibrosis & 505 & 52.7 \\
Primary pulmonary hypertension & 104 & 10.8 \\
Graft rejection & 81 & 8.4 \\
Bronchiolitis obliterans & 50 & 5.2 \\
Obstructive & 1 & .1 \\
Acute rejection & 1 & .1 \\
Restrictive & 3 & .3 \\
Nonspecific & 6 & .6 \\
Primary graft failure & 8 & .8 \\
Other & 12 & 1.3 \\
Primary bronchiolitis obliterans & 34 & 3.5 \\
Idiopathic pulmonary fibrosis & 32 & 3.3 \\
Pulmonary fibrosis other cause & 18 & 1.9 \\
Pulmonary vascular disease & 14 & 1.5 \\
Bronchiectasis & 9 & .9 \\
Eisenmenger's syndrome & 17 & 1.7 \\
COPD/emphysema & 7 & .7 \\
Surfactant protein B deficiency & 5 & .5 \\
Bronchopulmonary dysplasia & 4 & .4 \\
Other & 129 & 13.7 \\
\hline COPD, Chic
\end{tabular}

COPD, Chronic obstructive pulmonary disorder.
TABLE E2. Causes of death

\begin{tabular}{|c|c|c|}
\hline Cause of death & Frequency & Percent \\
\hline Graft failure & 169 & 34.6 \\
\hline Primary failure & 21 & 4.3 \\
\hline Rejection hyperacute & 2 & .4 \\
\hline Rejection acute & 5 & 1.0 \\
\hline Rejection chronic & 98 & 20.1 \\
\hline Technical & 3 & .6 \\
\hline Graft infection & 12 & 2.5 \\
\hline Recurrent disease & 2 & .4 \\
\hline Nonspecific & 26 & 5.3 \\
\hline Infection & 114 & 23.3 \\
\hline Bacterial & 48 & 9.8 \\
\hline Viral & 24 & 4.9 \\
\hline Fungal & 25 & 5.1 \\
\hline Mixed & 5 & 1.0 \\
\hline Other & 12 & 2.5 \\
\hline $\begin{array}{l}\text { Cardiovascular (myocardial infarction, cardiac } \\
\text { arrest, ventricular failure, cardiogenic } \\
\text { shock) }\end{array}$ & 18 & 3.7 \\
\hline Pulmonary & 84 & 17.1 \\
\hline Dehiscence & 3 & .6 \\
\hline Bronchiolitis & 23 & 4.7 \\
\hline Primary pulmonary hypertension & 2 & .4 \\
\hline Pulmonary embolism & 2 & .4 \\
\hline Respiratory failure & 47 & 9.6 \\
\hline Acute respiratory distress & 2 & .4 \\
\hline Other & 5 & 1.0 \\
\hline Cerebrovascular & 15 & 3 \\
\hline Stroke & 3 & .6 \\
\hline Hemorrhage (nonstroke) & 7 & 1.4 \\
\hline Brain anoxia & 3 & .6 \\
\hline Other & 2 & .4 \\
\hline Hemorrhage & 11 & 2.2 \\
\hline Gastrointestinal & 3 & .6 \\
\hline Intraoperative & 2 & .4 \\
\hline Postoperative & 3 & .6 \\
\hline Respiratory & 3 & .6 \\
\hline Malignancy & 14 & 2.8 \\
\hline Metastatic other specify & 1 & .2 \\
\hline Primary other specify & 1 & .2 \\
\hline Posttransplant lymphoproliferative disorder & 5 & 1.0 \\
\hline Lymphoma & 7 & 1.4 \\
\hline Intraoperative: not hemorrhage & 1 & .2 \\
\hline Renal failure & 2 & .4 \\
\hline Multiple organ failure & 25 & 5.1 \\
\hline Noncompliance & 4 & .8 \\
\hline Unknown & 33 & 6.8 \\
\hline
\end{tabular}

